\title{
Intestinal infarction following carbon monoxide poisoning
}

\author{
M. Balzan, J.M. Cacciottolo and A. Casha ${ }^{1}$ \\ Departments of Medicine and 'Surgery, St Luke's Hospital, Guardamangia, Malta
}

\begin{abstract}
Summary: A 65 year old patient admitted with carbon monoxide poisoning developed acute pulmonary oedema during treatment with hyperbaric oxygen. After initial recovery he developed extensive intestinal ischaemia which rapidly led to death. It is suggested that intestinal vasoconstriction due to left ventricular failure made the gut much more vulnerable to the hypoxic effects of carbon monoxide than the brain and heart.
\end{abstract}

\section{Introduction}

Carbon monoxide poisoning is a well-known cause of hypoxic injury to the central nervous system and myocardium. ${ }^{1}$ We report a case of carbon monoxide poisoning leading to extensive bowel ischaemia and death.

\section{Case report}

A 65 year old male was found unconscious in his bathroom. The butane gas water heater was later found to have a blocked flue. In the emergency room he was comatose and both plantar reflexes were upgoing. Carboxy-haemoglobin level $90 \mathrm{~min}$ utes after removal from the bathroom was $45 \%$. The electrocardiogram (ECG) on admission showed widespread ST segment depression maximal at $4 \mathrm{~mm}$ in lead V5. He was treated with $100 \%$ oxygen and 30 minutes later transferred to a hyperbaric unit.

On admission his chest X-ray showed emphysema and cardiomegaly. He had smoked 60 cigarettes a day up to 4 years previously, when he had developed a transient left hemiparesis due to ischaemic stroke, from which event he had recovered fully.

He received $100 \%$ oxygen at 2.6 atmospheres and his level of consciousness started improving. After about 30 minutes he became very short of breath and was immediately removed from the hyperbaric chamber. Severe pulmonary oedema was diagnosed and confirmed on chest X-ray. He was given $150 \mathrm{mg}$ of frusemide intravenously and had to be intubated and mechanically ventilated.

Correspondence: M. Balzan, M.D., M.R.C.P.(UK). Accepted: 12 October 1992
Carboxy-haemoglobin level was now 5\%. Although he was cold and clammy, his blood pressure was always above $160 / 100 \mathrm{mmHg}$. Diuresis was brisk and the chest X-ray became clear. Blood pressure remained stable at around $130 / 90 \mathrm{mmHg}$ for the first 12 hours and on the ECG, the ST segment became isoelectric.

About 12 hours after intubation, his blood pressure and central venous pressure started too drop rapidly while there was progressive distension of the abdomen with ileus. A plain abdominal $\mathrm{X}$-ray showed widespread small bowel distension with fluid levels. Despite aggressive fluid replacement, intranveous cefuroxime and netilmicin, and up to $20 \mu \mathrm{g} / \mathrm{kg} /$ minute of dopamine, resuscitation was unsuccessful and he died 36 hours after admission.

Autopsy showed advanced ischaemic necrosis of all abdominal organs including the liver, small and large bowel. There was no significant atheroma or thrombotic occlusion in the mesenteric vessels. Cerebral oedema and diffuse patchy subendocardial myocardial necrosis were also present.

\section{Discussion}

The generalized hypoxia due to the carbon monoxide poisoning put an increased load on an already compromised left ventricle causing acute pulmonary oedema. Hyperbaric oxygen therapy is also known to decrease cardiac output by causing peripheral vasoconstriction. ${ }^{2}$

Decreased blood flow in the splanchnic organs is one of the compensatory mechanisms occurring in heart failure to maintain adequate cerebral and coronary blood flow. ${ }^{3}$ As oxygen delivery to the tissues is greatly reduced in carbon monoxide poisoning, ${ }^{1}$ the intestines suffered a combined 
ischaemic and hypoxic insult. This explains why the hypoxic injury found at autopsy in the bowel was much more severe than in the more susceptible tissues of the brain and heart.

We could only find two other reported cases of documented bowel ischaemia associated with carbon monoxide poisoning. ${ }^{4,5}$ In both cases blood

\section{References}

1. Jackson, D.L. \& Menzes, M.D. Accidental carbon monoxide poisoning. JAMA 1980, 243: 772-774.

2. Grim, P.S., Gottlieb, L.J., Boddie, R.N. \& Batson, E. Hyperbaric oxygen therapy. JAMA 1990, 263: 2216-2220.

3. Schlant, J.S. \& Sonnenblick, E.H. Pathophysiology of heart failure. In: Willis Hurst, J. (ed.) The Heart. McGraw Hill, New York, 1990. pressure on admission was $90 / 60 \mathrm{mmHg}$ suggesting a state of circulatory collapse, with consequent visceral vasoconstriction. We suggest that shock or left ventricular failure in severe carbon monoxide poisoning may lead to bowel ischaemia which may be clinically more serious than central nervous system or myocardial ischaemia.

4. Watson, A. \& Williams, R. Anoxic hepatic and intestinal injury from carbon monoxide poisoning. $\mathrm{Br}$ Med J 1984, 289: 1113.

5. Janes, S. \& Lock, B. Carbon monoxide poisoning in childhood. Br Med J 1985, 291: 1725. 